\title{
Cell death during sepsis: integration of disintegration in the inflammatory response to overwhelming infection
}

\author{
Fabiano Pinheiro da Silva · Victor Nizet
}

Published online: 7 February 2009

(c) The Author(s) 2009. This article is published with open access at Springerlink.com

\begin{abstract}
Sepsis is a major health problem and a leading cause of death worldwide. In recent years, a crescendo of attention has been directed to the mechanisms of cell death that develop during this disease, since these are viewed as important contributors to the proinflammatory and antiinflammatory responses associated with poor outcome. Here we discuss mechanisms of cell death evident severe bacterial infection and sepsis including necrosis, apoptosis, pyroptosis, and extracellular trap-associated neutrophil death, with a particular emphasis on lymphocyte apoptosis and its contribution to the immunosuppressed phenotype of late sepsis. Individual bacterial pathogens express virulence factors that modulate cell death pathways and influence the sepsis phenotype. A greater knowledge of cell death pathways in sepsis informs the potential for future therapies designed to ameliorate immune dysfunction in this syndrome.
\end{abstract}

Keywords Sepsis - Apoptosis - Cell necrosis · Pyroptosis · Extracellular traps · Lymphocyte . Macrophage $\cdot$ Bacterial infection

F. Pinheiro da Silva

Department of Pediatrics, School of Medicine, University of California San Diego, Mail Code 0687, 9500 Gilman Drive, La Jolla, CA 92093-0687, USA

e-mail: fdasilva@ucsd.edu

\section{Nizet $(\bowtie)$}

Skaggs School of Pharmacy \& Pharmaceutical Sciences, University of California San Diego, Mail Code 0687, 9500 Gilman Drive, La Jolla, CA 92093-0687, USA

e-mail:vnizet@ucsd.edu

\section{Introduction}

Sepsis remains the leading cause of death in intensive care units (ICUs), despite remarkable advances in treatment of critical illness and outstanding progress in all other aspects of ICU medicine [1]. Current mortality rates attributable to sepsis are in the $30-40 \%$ range and increase to $\sim 70 \%$ in specific patient groups such as the elderly and those with chronic underlying diseases. These disappointing statistics reflect the multiplicity of agonistic and antagonist interactions between bacterial pathogens and host cells, yielding complex inflammatory responses during the course of disease that are far from completely understood. Indeed, only by probing deeper into the molecular and cellular mechanisms that trigger the clinical features observed in sepsis patients can we anticipate the development of more effective medicines and improved survival.

Sepsis, according to the actual consensus, is a disease defined by clinical criteria. These criteria were defined by specialists in the field, who joined in 1991 for a meeting organized by the "American College of Chest Physicians" and by the "Society of Critical Care Medicine", aimed to standardize the nomenclature, which was becoming confusing, due to the indiscriminate use of terms as bacteremia, septicemia and sepsis [2]. The currently accepted nomenclature defines sepsis as a systemic inflammatory response syndrome (SIRS) due to infection and characterized by the presence of at least two parameters: hypothermia or fever, tachycardia, leukocytosis or leukopenia, or more than $10 \%$ immature leukocytes in the blood. "Severe sepsis" is recognized by the presence of organ dysfunction plus evidence of blood perfusion abnormalities (e.g., lactic acidosis, oliguria, altered consciousness) and episodes of hypotension, while "septic shock" exists when blood perfusion abnormalities are not responsive to vigorous fluid administration. 
Septic shock typically leads to multiple organ dysfunction syndrome (MODS), where failure of three or more organ systems develops in the critically ill patient and homeostasis cannot be maintained without life support techniques.

In the 1980s, prevailing thought attributed the high mortality of sepsis to an explosive and overwhelming systemic inflammatory response. In these models, bacterial components would hyper-activate the immune system, inducing an inflammatory response so potent that it could eventually lead the host to die. This hypothesis inspired several clinical trials aiming to down-regulate and control inflammation, e.g., with high dose corticosteroids or anticytokine agents. The disappointing results of such trials, indeed in some cases mortality was even increased by the anti-inflammatory strategies, revealed that the proposed concept was wrong, or at least incomplete, and certainly underappreciated the fact that sepsis is a heterogeneous disease, affecting both young and the elderly, as well as patients with different comorbidities [3].

Roger Bone, in the 1990s, trying to explain why those early clinical trials had failed, proposed the concept of the "Compensatory Antagonistic Response Syndrome (CARS)", where he defended the idea that after the initial explosive inflammatory response, an antagonistic antiinflammatory response would take place, leading sepsis patients to succumb due to secondary infections or become unresponsiveness to treatment interventions [4, 5] (Fig. 1). Indeed, septic patients possess many signs of deficient immune response, including ineffective antigen presentation, T-lymphocyte hyporesponsiveness, and decreased Th1 cell proliferation; the term "immunoparalysis" is commonly applied to this state of immune anergy observed in late sepsis. As will be outlined in detail, the phenotype of

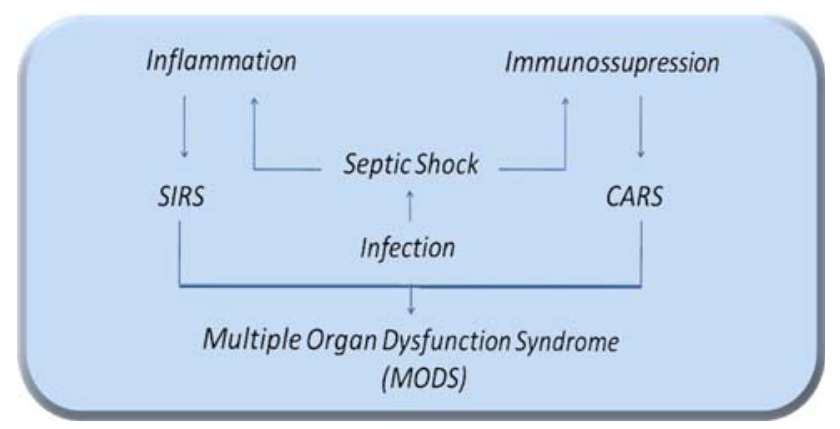

Fig. 1 The balance of inflammation, and immunosuppression during sepsis. In general, at an earlier stage, patients develop and overwhelming inflammatory response (SIRS). Later, however, septic patients show signs of anergy or immunosuppression with an increased incidence of secondary infections (CARS). The elderly and patients with comorbidities shift faster towart CARS, while younger patients, generally, can present with prolonged SIRS. Both conditions can culminate in multiple organ dysfuntion syndrome $(M O D S)$. SIRS Systemic inflammatory response syndrome; CARS compensatory antagonistic response syndrome the septic patient is also characterized by increased numbers of apoptotic cells-mainly lymphocytes, dendritic cells and epithelial cells. Since it is well established the presence of apoptotic cells cause lymphocytes and monocytes to significantly lesser amounts of pro-inflammatory cytokines, the processes of cell death and immunosuppression are intricately related in sepsis.

Although some have proposed that organ failure and immunosuppression in sepsis are a direct consequence of apoptotic cell death, the diversity and complexity of the clinical syndrome often make it difficult to ascertain which phenomenon occurs first. Recent years have witnessed an explosion in information regarding cell death mechanisms, including they way they are induced and manipulated by invasive bacterial pathogens. Here we will review some key aspects of the tightly regulated pathways that govern cell death decisions during the course of a septic insult. In this context, an imprecision of the term immunoparalysis can be appreciated, since apoptotic and counter-inflammatory pathways need to be continuously activated for the perpetuation of this dynamic process.

\section{Fundamental mechanisms of cell death relevant to sepsis}

Necrosis, apoptosis and autophagy

Dying cells can be necrotic, apoptotic (type-1 programmed cell death), or autophagic (type-2 programmed cell death); the latter phenomenon is often reversible. During necrosis, cells exhibit swollen cytoplasm, disorganized organelle structures, ruptured membranes and a lytic appearance to their nuclei (karyolysis) [6]. In contrast, a hallmark features of the apoptotic cell is chromatin condensation, which later proceeds to fragmented nuclei (karyorrhexis) and formation of apoptotic bodies, often in the setting of an intact plasma membrane and organelles. Autophagy is a process that enables the cell to degrade self components in order to recycle or eliminate excessive cytoplasmic content; in critical situations like starvation, autophagy can preserve cell life. Autophagy is characterized by formation of autophagosomes-large double membrane vesicles that engulf cytosol and organelles. Autophagosomes subsequently fuse with lysosomes, and are degraded without further cell damage nor alarm signals [7]. It has been suggested that once a cell's autophagic capacity is overwhelmed, apoptosis is triggered.

The three different modes of cell death appear to be related mechanistically. The mitochondria, for example, can be a promoter of autophagy, apoptosis or necrosis. The resultant cell death pathway depends on the magnitude of mitochondrial membrane permeability triggered during 
stress by different factors, such as calcium ions, inorganic phosphate and free fatty acids. Perturbations in permeability can lead to ATP depletion and swelling or rupture of the mitochondrial outer membrane. If permeability changes are mild, an autophagy program can be summoned, recycling the mitochondria before further damage ensues. If cytochrome $c$ and other pro-apoptotic molecules, like apoptosis inducer-factor (AIF), second mitochondriaderived activator of caspases/direct IAP-binding protein (Smac/Diablo) and pro-caspases-2, -3, -8 and -9 reach the cytosol, pathways that lead to apoptosis are activated. If ATP drops precipitously, however, leading to plasma membrane failure and leakage of intracellular enzymes, necrosis occurs [8].

\section{The inflammatory response to necrosis}

The inflammatory response to necrosis remains a poorly understood phenomenon. Injured cells release a variety danger signals - some of these molecules are recognized by receptors, stimulating the production of pro-inflammatory mediators. The response mechanisms triggered by necrotic cell death are particularly complex in sepsis. Since even sterile cell death induces inflammation, a combination of bacterial stimuli and host stimuli, even those elicited in sterile sites, may be implicated in the inflammatory response during a septic event. Furthermore, over time, if apoptotic cells are not rapidly ingested by phagocytes, they can undergo a process called secondary necrosis, releasing their intracellular contents and inducing inflammation [9].

Although it is possible that cytokines might be released directly upon cell death, only certain types of cells store these molecules, so it is likely that other molecular intermediates are also pivotal in this process. Many candidates have been proposed, including HMGB1, uric acid, heat shock proteins, DNA-chromatin complexes, antimicrobial peptides, and others. HMGB1 is a nuclear protein expressed constitutively, binding to DNA and regulating gene transcription. It is released by necrotic cells, but not apoptotic cells [10], and has been shown to stimulate $\mathrm{TNF} \alpha$ secretion by monocytes. While anti-HMGB1 antibodies injected into mice were found to reduce inflammation in an animal model of drug-induced hepatitis [10], necrotic cells lacking HMGB1 are still capable of inducing inflammation [11]. Uric acid is an intracellular molecule whose biologically active form, monosodium urate (MSU) microcrystals, is generated upon release to the cytosolic compartment. MSU has recently been identified as a strong inducer of IL-1 $\beta$ secretion [12]. DNA-chromatin complexes [13] and heat shock proteins $[14,15]$, have been shown to stimulate proinflamatory cytokines production in certain conditions, and cationic antimicrobial peptides [16] and various purine, such as adenosine and ATP [17], also have chemotactic activity.
Specific receptors involved in amplifying the host inflammatory response in response to cell necrotic are beginning to be identified. Toll-like receptor 3 (TLR-3), best recognized as a receptor for viral double-stranded RNA, allows macrophages to recognize byproducts of necrotic (but not apoptotic) neutrophils, thereby stimulating the generation of pro-inflammatory cytokines [18]. Another recent example of a receptor involved in this process is macrophage-inducible C-type lectin (Mincle), which has been shown to sense nonhomeostatic cell death and induce the production of proinflammatory cytokines, driving neutrophils to damaged tissues [19].

\section{Caspase-dependent apoptotic cell death}

Apoptotic cell death holds particular importance in sepsis because it affects immune cells, which are critical during the course of infection. Regulation of cell death is an essential aspect of the host response to infectious stress and is therefore maintained under tight control; caspases are the principle orchestrators of these decision points. Over a dozen caspases have been identified and approximately two-thirds have been suggested to function in apoptosis [20]. Many caspases also participate in additional cellular functions, as cytokine production, differentiation and proliferation [21]. Caspases are cysteine proteases activated during apoptotic death and are highly conserved through evolution, from humans to insects. Synthesized as enzymatically inert zymogens, caspases are composed of three domains: an $N$-terminal domain, a p20 and a p10 domain, the mature enzyme being a heterotetramer containing two p20/p10 heterodimers and two active sites. Activated by proteolytic cleavage, initiator caspases start an avalanche of increasing caspase activity by processing and activating effector caspases [22]. Effector caspases then cleave and inactivate vital cellular components, such as DNA synthesis, cleavage and repair enzymes, MDM2 (an inhibitor of p53), cell cycle regulators, cytoskeletal proteins and protein kinase $\mathrm{C} \delta$ [23, 24].

There are three pathways for induction of apoptotic cell death that culminate in caspase activation: the deathreceptor pathway, the mitochondrial pathway and the endoplasmic reticulum pathway. The death receptor pathway (also known as extrinsic pathway) is initiated on the plasma membrane by ligand binding, followed by receptor oligomerization. Ligands include proteins as Fas and TNF $\alpha$. The best characterized death receptors are CD95 (Fas or ApoI) and TNFRI (p55 or CD120a) [25]. Signaling by some death receptors, like TNFRI, also mediates different biological outcomes, like inflammation, depending on cell type, genetic and environmental factors [26]. Once Fas (CD95) aggregates, it can recruits FAS-associated death domains (FADD) to form membrane-bound 
complexes. These complexes recruit procaspase- 8 , the low intrinsic protease activity of this enzyme being considered enough to allow the various molecules recruited to the same site to activate each other, ultimately leading to caspase- 3 activation and cell death. TNFRI oligomerization, however, initially recruits RIP1, TRADD, TRAF2 and cIAP1 to form complex I, which tranduces signals leading to NF- $\kappa \mathrm{B}$ translocation to the nucleus. At later time points, RIP1, TRADD and TRAF2 dissociate and TNFRI recruits FADD and caspase-8 to form complex II, which induce apoptotic cell death [26] (Fig. 2).

The mitochondrial pathway is triggered by cell stress, which leads to activation of proapoptotic members of the Bcl-2 family, such as Bim, Noxa, Puma, Bid and Bad. These events, in turn, sequestrate antiapoptotic Bcl-2 family members, including Bcl-2, Mcl-1, Bcl-XL, thereby enabling Bax and Bad oligomerization. The three dimensional structure of $\mathrm{Bcl}-\mathrm{x}_{\mathrm{L}}$ reveals structural similarities to bacterial pore-forming toxins [27] and it has been shown that $\mathrm{Bcl}-2, \mathrm{Bcl}-\mathrm{x}_{\mathrm{L}}$ and $\mathrm{Bax}$ can form ion channels [28, 29]. Indeed, activated $\mathrm{Bax}$ and $\mathrm{Bad}$ form pores in the mitochondrial membrane, inducing the release of pro-apoptotic molecules from the mitochondria, such as cytochrome $c$, Smac/Diablo, IAP (inhibitor of apoptosis protein), AIF (apoptosis-inducing factor), Omi/HtrA2 and endonuclease G. When cytochrome $c$ enters in the cytosol, it is able to activate caspase-9 and, in conjunction with APAF-1 and dATP, form a complex called the apoptosome, which finally activates caspase- 3 , reaching the point where the extrinsic and intrinsic pathways of apoptosis converge. Smac/Diablo promotes apoptosis indirectly, by binding to and antagonizing members of the inhibitors of apoptosis protein (IAP) family [30]. Apoptosis-inducing factor (AIF) and endonuclease- $G$ induce apoptosis in a caspase-independent manner. On the other hand, many anti-apoptotic molecules, such as Bcl-2, Bcl-X and Akt act to maintain mitochondrial integrity, keeping the pro-apoptotic molecules inside. Indeed, a number of proteins with structural similarity to Bcl-2 have been discovered in the last decade. The link between the extrinsic and intrinsic pathways occurs when caspase- 8 cleaves Bid to t-Bid, which is then able to translocate into mitochondrial membranes and promote oligomerization of Bax.

Endoplasmic reticulum (ER) stress may ultimately lead to cell death. Endoplasmic stress is induced by accumulation of unfolded protein aggregates or excessive protein trafficking. The precise function of caspase-12 in this pathway has been investigated with conflicting results [31, 32]. Caspase- 12 activates caspases- $-3,-8$ and -9 , and is itself activated by $\mathrm{Ca}^{+2}$ and oxidant stress [33]. Caspase-12deficient mice clear bacteria more efficiently than wild-type controls and have an enhanced production of IL-1 $\beta$ and IL-18, but not TNF $\alpha$ or IL-6. Thus, caspase-12 has been proposed as a decoy caspase, blocking caspase-1 activation and increasing survival in septic shock [34]. Further studies, however, are necessary to establish the role of caspase-12 in endoplasmic reticulum stress-mediated apoptosis.

\section{Caspase-independent apoptotic cell death}

Although caspases regulate most apoptotic processes, there are some exceptions. In particular, cathepsins can be
Fig. 2 Apoptosis pathways in sepsis. Representation of the classical death-receptors, mitochondrial, and endoplasmic reticulum pathways.

Inflammasomes and lysosomal pathways are also illustrated

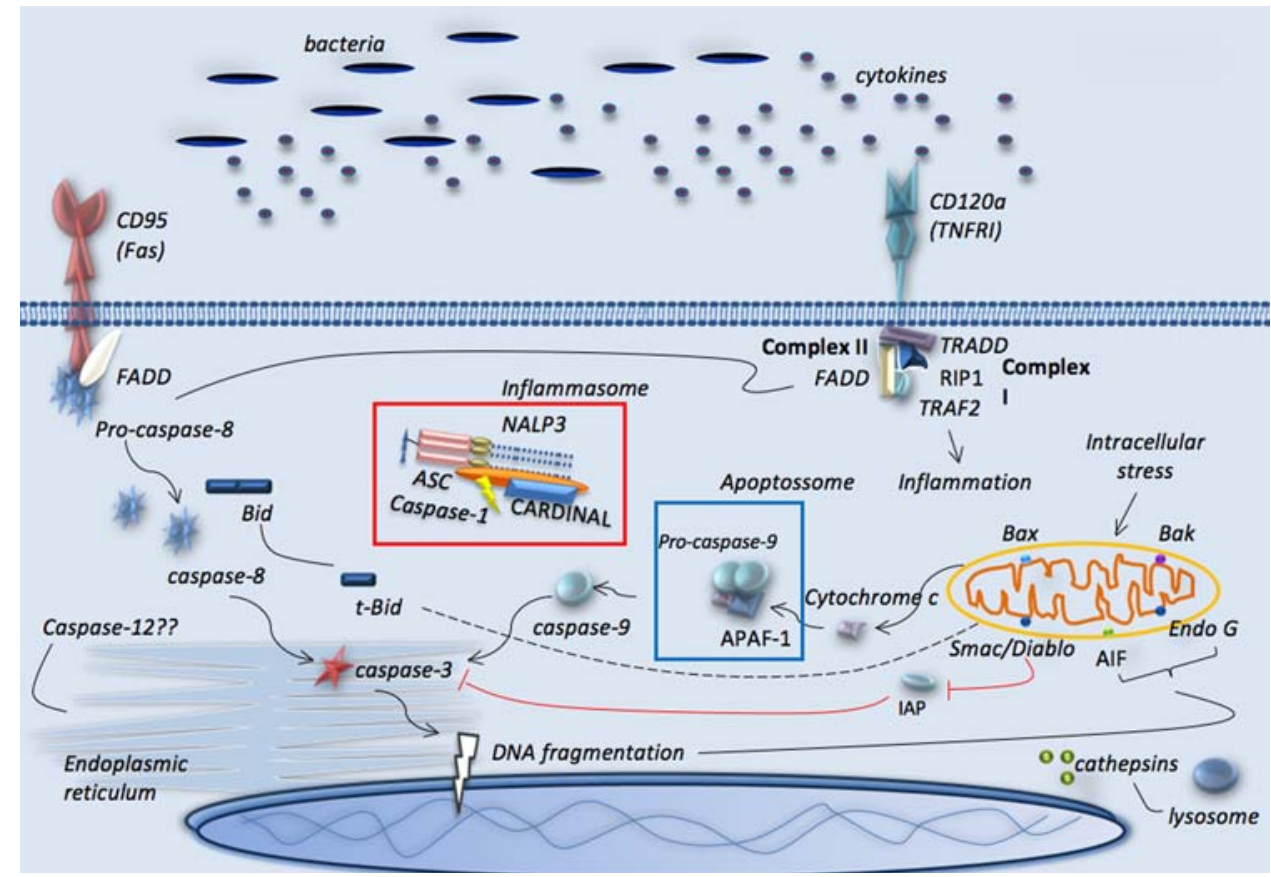


responsible for apoptosis in a caspase-independent manner $[35,36]$. Cathepsins are mostly cysteine proteases, even though the term also includes serine proteases (cathepsins A and G) and aspartic proteases (cathepsins D and E). While caspases are localized predominantly in the cytoplasm, cathepsins reside inside the lysosomes. Cathepsins are involved in a number of important processes, including intracellular protein turnover, antigen processing, proprotein and hormone activation [37, 38]. Cathepsins are synthesized as inactive proenzymes and when released into the cytoplasm, they can catalyze enzymatic cleavage of different vital substrates, inducing apoptotic cell death. Cathepsins B, L and D have been found to play an important role in the regulation of apoptosis [39]. Lysosomal permeabilization seems to be induced by different mechanisms, depending on the cell type or stimulus. Activation of TNFR-I, for example, results in production of sphingosine, which induces lysosomal rupture [40]. Reactive oxygen species damage have also been related to lysosomal leakage [41]. Cathepsins may cause direct mitochondrial damage, mediating cytochrome $c$ release and, in parallel, Bid and Bax activation. In addition, cathepsins may catalyze the degradation of critical substrates for cell survival. Importantly, while moderate lysosomal rupture is associated to apoptotic cell death, massive rupture was found to induce necrotic cell death [42].

\section{Bacterial pathogen influences on host cell death pathways}

Modulation of host cell apoptosis

Certain bacterial pathogens have developed strategies to induce rapid apoptosis of host cells including phagocytic cells, allowing them to reduce the release of pro-inflammatory signals and survive intracellular killing. A family of pore-forming bacterial cytotoxins, including those elaborated by the leading pathogens Streptococcus pyogenes, Staphylcoccus aureus, and Listeria monocytogenes are one class of agents triggering cell death phenotypes. For example, $S$. pyogenes induces rapid, dose-dependent apoptosis of neutrophils [43] and macrophages [44]. This cell death pathway involves apoptotic caspases and requires GAS internalization by the phagocyte. Analysis of GAS virulence factor mutants, heterologous expression, and purified toxin studies identify the pore-forming cytolysin streptolysin ' $\mathrm{O}$ ' (SLO) as necessary and sufficient for the apoptosis-inducing phenotype. Ultrastructural evidence of membrane remodeling, loss of mitochondrial depolarization and cytochrome $c$ release indicate a direct attack of SLO on the mitochondria initiates the intrinsic apoptosis pathway [44]. The net effect of the accelerated apoptosis reduces bacterial killing, diminished pro-inflammatory cytokine release, and increased bacterial virulence, while caspase inhibition blocked macrophage apoptosis and promoted bacterial clearance. GAS also elaborate the potent heterocyclic peptide cytolysin streptolysin S (SLS) [45] which can deplete host phagocytes and help promote bacterial survival [46] through a proinflammatory, calpaindependent cell death pathway [47]

L. monocytogenes lyses the phagosomal membrane and escapes into the cytosol to initiate an intracellular infection, a process dependent on the pore-formin toxin listeriolysin O (LLO). Subsequently, intracellular L. monocytogenes induces LLO-dependent apoptosis in different cell types, including hepatocytes [48], lymphocytes [49] and dendritic cells [50]. LLO might insert into the mitochondrial membrane, allowing release of cytochrome $c$ or efflux of $\mathrm{Ca}^{2+}$, activating calpain or caspases. S. aureus alpha-toxin, structurally related to SLO and LLO, induces apoptosis in epithelial cells through activation of both caspase- 3 and caspase-8 [51, 52].

Legionella pneumophila, the causative agent of Legionnaire's disease, induces caspase-3-dependent apoptosis in macrophages and alveolar epithelial cells, through an effector delivered by the Dot/Icm type IV-like secretion system [53]. In an immune evasion strategy targeting the lysosomal pathway, the toxic metabolite pyocyanin, produced by $P$. aeruginosa, accelerates neutrophil apoptosis by inducing lysosomal membrane rupture, mitochondrial membrane permeabilization and caspase activation [54]. A number of other Gram-negative bacterial pathogens produce the so-called cytolethal distending toxin (CDT), which exhibits a DNAse 1-like activity that generates DNA strand breaks and leads to G2 cell cycle arrest followed by apoptosis in immune cells [55]. Finally, activation by bacterial superantigen such as $S$. aureus enterotoxin B and $S$. pyogenes can delete specific $\mathrm{T}$ and $\mathrm{B}$ cell populations through increased apoptosis, contributing to the pathogenesis of potentially fatal toxic shock syndrome [56-58].

Interestingly, there are certain situations were host cell apoptosis may serve a beneficial function in immune defense against infection. An example is the rapid apoptosis of lung epithelial cells recognized during $P$. aeruginosa pulmonary infection, which occurs through a Fas/Fas ligand-dependent pathway [59]. Deficiency of Fas or Fas ligand leads to reduced lung epithelial cell apoptosis in vitro and in vivo, but these knockout mice are more susceptible to development of fatal pseudomonal sepsis. Here death receptor pathway-mediated apoptosis aids in $P$. auruginosa clearance by segregation of the bacteria into apoptotic bodies, which are rapidly phagocytosed by other cells, and by Fas-mediated induction of cytokine and antimicrobial peptide release, which can amplify the host immune 
Fig. 3 Cell death influences on progression of sepsis. Bacterial infection activates macrophages, inducing the secretion of proinflammatory mediators, which activate the three classical apoptosis pathways. During sepsis, dendritic cells, B lymphocytes and epithelial cells are the cells types predominantly affected. Apoptosis induces antiinflammatory response, which can culminate in CARS ("Compensatory Antagonistic Response Syndrome") and MODS ("Multiple-Organ Dysfunction Syndrome"). Other common mechanisms of cell death in sepsis, include NETosis, necrosis and pyroptosis, and proinflammatory in nature

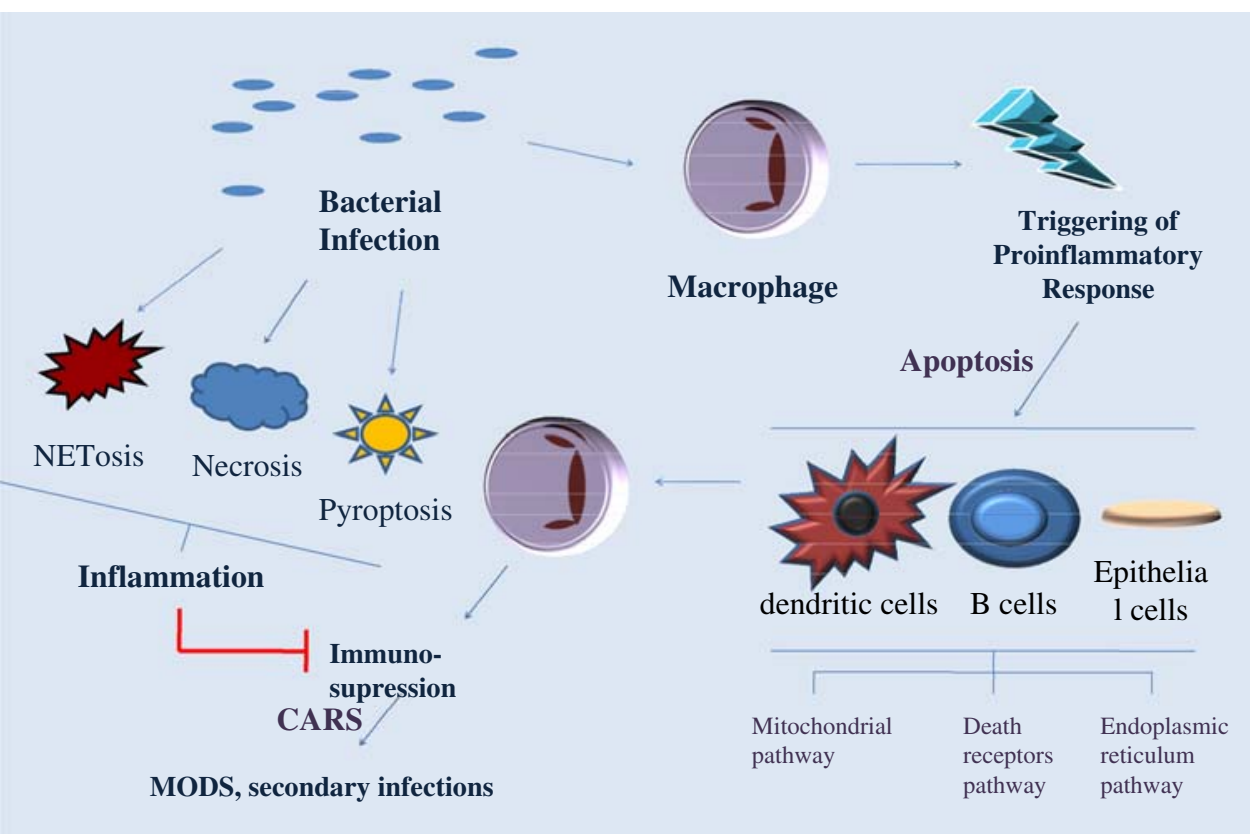

response and effects extracellular killing of the pathogen [59].

Pyroptosis and the inflammasome

Rapid macrophage death induced by Salmonella bacteria resembles necrosis, but caspase-1 activation is intimately related to this process, distinguishing it from any form of accidental cell death [60]. This particular pro-inflammatory programmed cell death, therefore, seems to be an alternative pathway for removing unwanted cells without aborting the recruitment of additional cells or cellular functions crucial to fighting infection. The term "pyroptosis" has been proposed as a name for this process [61, 62]. Caspase1 , as opposed to caspases $-3,-8$ and -9 , is an inflammatory caspase. This subclass of caspases involved in cytokines processing and release, also includes caspases-4, -5, -11 and -12 . Members of the NOD-receptor family, including the NALPs, NAIP and IPAF, promote the assembly of multiprotein complexes, called inflammasomes, which play a key role in the activation of the inflammatory caspases. These molecular platforms integrate cellular signals and promote dimerization of inflammatory caspases, leading to the formation of active proteins, the processing of IL-1b and IL-18, and the initiation of additional signaling pathways.

Caspase-11 has been suggested to act as an essential activator of caspase-1 and as its obligate partner [63]. Indeed, caspase- 11 deficient mice were unable to produce IL-1 $\beta$ and IL-18 in response to LPS stimulation [64]. This requirement, however, seems to be stimulus-specific, since caspase- 1 could be activated normally in the absence of caspase-11 following Listeria infection [65]. The human caspase-1 gene cluster contains caspase- 1 and four additional genes encoding decoy caspases: cop, incal, inca 2 and iceberg, which presumably play a role in negatively regulate processing of pro-IL- $1 \beta$; these decoy receptors are absent in the mouse genome [66].

The NALP inflammassomes are the best studied so far, and two types have been identified. The NALP1 inflammasome is composed of NALP1, the adaptor protein ASC, caspase- 1 and caspase-5, whereas the NALP2/NALP3 inflammasome composed of NALP2 or NALP3, plus CARDINAL, ASC and caspase-1, but not caspase-5 [67]. Each NALP inflammasome can sense both pathogen-recognition patterns and danger-associated molecular patterns [68]. Low concentrations of potassium are associated with inflammasome activation, independent of the primary stimulus. Indeed, pore-forming bacterial toxins such as Staphylococcus aureus $\alpha$-toxin activate the inflammasome in a potassium-dependent manner [69]. Franciscella and Listeria, through a type III-secretion system or the production of pore-forming toxins, are also able to gain entry into the cytosol and activate caspase-1 [70]. Cytoplasmic NALP inflamassomes can detect intracellular infection through recognition of molecular patterns, cooperating with Toll-like receptors (TLRs) pathways to generate an appropriate response to pathogens or cellular stress [71].

Important intracellular crosstalk occurs between TLRs and the inflammasomes. While the first stimulus (TLRdependent) seems important for generation of pro-IL-1 $\beta$, the second one allows caspase- 1 activation and subsequent proteolytic maturation and secretion of IL-1 $\beta$. Salmonella [72] and Legionella [73], however, induce assembly of the 
IPAF inflammasome, while the anthrax lethal toxin is recognized by the NALP1 inflammasome [74]. Thus, depending on the context, the activity of caspase- 1 can induce cytokine secretion or cell death [75]. Caspase-1 activation needs to be maintained under tight regulation to control the magnitude of the inflammatory response, avoiding its deleterious effects, such as occurs in sepsis. Supporting this notion, it has been shown that both caspase-1 and caspase-11 deficient mice are more resistant to endotoxic shock than wild-type controls $[64,76]$.

Induction of neutrophil extracellular trap-associated cell death

Neutrophil extracellular traps (NETs) are structures composed of chromatin and granule proteins that are released as the cell dies, allowing neutrophils to entrap and kill microorganisms extracellularly "postmortem" [77]. In this new form of cell death [78, 79], colloquially dubbed "NETosis", the nuclei of neutrophils lose their shape, the nuclear membrane disintegrates, and the chromatin comes into direct contact with the cytoplasm, thus homogenizing with the granular proteins. Subsequently, the cell membrane breaks and NETs are released, trapping bacteria in tissues and in the circulation, particularly in the hepatic and pulmonary sinusoids. Indeed, with their lower shear stress and smaller cross-sectional areas, sinusoids appear to serve as an optimal site for NETs formation. Moreover, platelet binding to neutrophils is critical for neutrophil activation and further NETs formation in these vessels [80, 81]. This process of NETosis is distinct from necrosis or apoptosis, and neither apoptosis nor necrosis induced NET formation. NETs show disintegration of the nuclear envelope, mixing of nuclear and cytoplasmic material, loss of internal membranes and disappearance of cytoplasmic organelles; yet in NETs, there is no DNA fragmentation, a hallmark of apoptosis. Differently from the classical forms of cell death, It remains unclear why only granular proteins, but not cytoplasmic proteins, bind to NETs. Released NETs bind fungi, Gram-positive and Gram-negative bacteria [82, 83]. NET formation depends on generation of reactive oxygen species, and consequently patients with NADPH oxidase deficiency (chronic granulomatous disease) exhibit a deficiency in NET formation that may further contribute to their predisposition to severe and chronic infections.

The presence and kinetics of free circulating neutrophilderived DNA/NETs appear to serve as a useful marker of sepsis disease severity and multiple organ failure in patients following multiple traumas [84]. Specific bacterial products, such as the surface expressed $\mathrm{M}$ protein of $S$. pyogenes, or host chemokines, such as IL-8, can induce the production of NETs $[85,86]$. It is now recognized that certain leading leading bacterial pathogens, including
Streptococcus pneumoniae and S. pyogenes, express broadspectrum DNAses that have recently been shown to dissolve NETs, allowing pathogen to escape entrapment and spread to produce systemic infection in the host into the host [87-89].

\section{Cell death influences on sepsis progression and immune suppression}

As described in the introduction, the initial hyperinflammatory response in the first $24-72 \mathrm{~h}$ of sepsis is followed by a protracted state of immunosuppression where failure to eradicate the inciting infection and secondary nosocomial infections, often with opportunistic pathogens such as Pseudomonas aeruginosa or Candida albicans, are frequent clinical manifestations. Coincident with this state of diminished immune function, autopsies of septic patients in adult, pediatric and neonatal age groups have revealed extensive apoptosis of splenic lymphocytes [90-92]. Lymphocyte apoptosis is also appreciated as an early event in peripheral blood of septic patients, with the degree of apoptosis correlating to the severity of sepsis symptoms, and profound and persistent lymphopenia a harbinger of poor outcome [93]. Lymphocyte populations depleted through apoptosis in septic patients include B cells and CD4 + T cells [90]. Apoptotic loss of splenic follicular dendritic cells is also apparent, however, macrophages populations are notably preserved [94]. Corroborating the human findings, in experimental cecal ligation and puncture (CLP), a well-established model system for the study of polymicrobial sepsis in the mouse, apoptosis is induced in the spleen, thymus, lung and intestinal Peyer's patches $[95,96]$. By analysis of responses in endotoxin-sensitive and -resistant mice, these studies identified the widespread apoptosis of sepsis to occur through an LPS-independent pathway(s). In addition to depletion of lymphocytes, sepsis induces apoptosis of a large number of epithelial cells. Gut [97], lungs [98] and liver [99] are the predominant organ sites of increased epithelial cell apoptosis; endothelial cells in these tissues are affected to a certain extent as well [100].

It has been suggested that apoptosis can contribute to the state of immunosuppression in prolonged sepsis in at least two major fashions: the programmed cell death of key effector cells, as described above, or alternatively, the capacity of apoptotic cells to induce anergy and Th2responses in surviving immune cells such as macrophages and dendritic cells [101]. When macrophages or dendritic cells phagocytose apoptotic cells, both cell types express lower levels of co-stimulatory molecules than expected [102], while releasing large amounts of anti-inflammatory cytokines such as transforming growth factor-beta (TGF- $\beta$ ) 
and IL-10 [103]; high levels of the latter cytokine a particularly poor prognostic factor in sepsis patients [104]. The TAM family of receptors (Tyro3, Axl, Mer tyrosine kinase) are implicated in apoptotic cell recognition, as compound deficiencies of these molecules result in defective apoptotic cell clearance, increased $\mathrm{TNF} \alpha$ production, and spontaneous hyperactivation of macrophages and dendritic cells [105]. Other candidate's receptors that may mediate apoptotic cell recognition to suppress immune responses include $\mathrm{CD} 35$, avb5 integrin, $\mathrm{C} 1 \mathrm{q}$ and the phosphatidylserine receptor [106].

In elegant adoptive transfer experiments using the CLP model, parenteral administration of necrotic cells increased IFN- $\gamma$ levels and decreased mortality, while administration of apoptotic cells had the opposite effect, reducing IFN- $\gamma$ levels and greatly increasing mortality [107]. In these studies, the beneficial effects of necrotic cells were blocked in IFN- $\gamma$ deficient animals or with anti-IFN- $\gamma$ antibodies [107]. These results support the clinical evidence that the pathways of cell death that transpires in early sepsis are likely to exert profound influences on subsequent immune competence and clinical outcome, with high levels of apoptosis being particularly deleterious.

Mitochondrial dysfunction apparent during sepsis and other critical illnesses contributes to a proclivity for cell death and organ failure. In particular, nitric oxide (NO), a proximal mediator of the inflammatory cascade in sepsis, exerts inhibitory effects on mitochondrial electron transport chain complexes. Histopathologic evidence in splenic autopsies of septic patients suggests the mitochondrial pathway plays a prominent role in lymphocyte apoptosis [90]. Furthermore, skeletal muscle ATP concentrations were significantly lower in patients with sepsis who subsequently died than those who ultimately survived [108], a finding which could be correlated to overproduction of NO and depletion of cellular antioxidant capacity. In a rat CLP model, oxidative stress within skeletal muscles develops early in the onset of sepsis, leading to inhibition of active mitochondrial respiration [109]. Bcl-2 transgenic mice, which selectively overexpress an anti-apoptotic protein that acts to preserve mitochondrial integrity, show improved survival in the CLP model compared to normal mice [110].

Along with mitochondrial pathway, the death receptor pathway also plays an important role in provoking lymphocyte apoptosis during sepsis. Mice with defects in the Fas/Fas ligand signaling pathway through genetic engineering or pharmacological blockade show decreased levels of sepsis-induced lymphocyte apoptosis [111, 112], as well as increased survival in the CLP model [113]. Furthermore, immunohistologic analyses and study of caspase activation patterns in apoptotic lymphocytes isolated from baboons with E. coli-induced septic shock [114] as well as a large series of human sepsis patients [115] are consistent with contributions from both the mitochondrial and death-receptor pathways of apoptosis. However, inhibition of B cell apoptosis by specific targeting of Fc $\gamma$ RII (CD32), an ITIM-containing Fc receptor, was insufficient to reduce mortality in the mouse CLP model, despite leading to a significant drop in apoptotic cells numbers [116]. Thus it is likely that B cell numbers need to be dramatically reduced in sepsis to affect overall survival; the anti-inflammatory response triggered in $\mathrm{T}$ cells following their interacting with apoptotic B cells, while poorly understood, could help explain this apparent paradox.

\section{Therapeutic perspectives on cell death pathways in sepsis}

Based on the animal studies and on patients findings observed until now, abrogation of apoptosis during sepsis seems to be an interesting therapeutic strategy, in order to prevent death of immune cells and maintain the integrity of the mucosal surface. However, sepsis is a complex disease and only specific subpopulations might benefit form different therapeutic strategies or the introduction of a certain therapy at different time points. Indeed, in the clinical setting, very few treatments have been proven to provide significant benefit so far. Administration of insulin [117] and activated protein C [118] are among these established therapies. Interestingly, these treatments have the theoretical potential to target apoptotic pathways, and it is likely reduced apoptosis may contribute to their therapeutic benefit [119]. For example, in addition to its anti-inflammatory effect, administration of insulin to septic patients can induce cell proliferation, probably by activation of Akt/ PKB pathways [120]. Activated protein C has similarly been shown to counter the induction of apoptosis in animal studies and in vitro studies in human endothelial and monocyte cell lines [121, 122].

Caspase inhibition has been a focus of anti-apoptotic therapy in sepsis with encouraging results in animal models. Treatment with z-VAD ( $N$-benzyloxycarbonyl-Val-Ala$\operatorname{Asp}(O$-methyl) fluoromethyl ketone), a broad-spectrum caspase inhibitor, improves the survival of septic mice [123]. The administration of siRNA directed against the caspase- 8 gene transcript also improves survival in the mouse CLP model [111]. However, there are important theoretical and pharmacological considerations that may limit the utility of caspase-targeted approaches. First, since only a very small amount of activated caspase- 3 can initiate DNA fragmentation and apoptosis, the pharmacological blockade would have have to be highly potent and penetrant [101], while caspase inhibitors at large doses can have nonspecific side effects including cytotoxicity. Anti-retroviral protease inhibitors have also been tested in murine sepsis 
and shown to increase survival, reduce lymphocyte apoptosis, early $\mathrm{TNF} \alpha$ and late IL-6 and IL-10 levels [124].

Targeted with the death receptor pathway is another intriguing approach to ameliorate sepsis-associated apoptosis and immune dysfunction, especially since high levels of Fas expression are evident in the tissues of septic animals. In mouse CLP studies, inhibition of Fas signaling using a Fas-based fusion protein (FasP, Amgen, Inc.) to block receptor ligation reduced lymphocyte apoptosis, improved organ blood flow, prevents hepatic injury, and reduces mortality [113, 125]. The results on blocking lymphocyte apoptosis and hepatic injury have been reproduced in an approach employing siRNA targeting Fas [111].

Finally, the pharmacological targeting mitochondrial reactive oxygen species (ROS), whose production is characteristic of early stages of apoptosis, offers another potential therapeutic approach to reduce sepsis-induced cell death. Nitroxides, such as 4-hydroxy-2,2,6,6,-tetramethyl piperidine-1-oxyl (TEMPOL) act as effective ROS scavengers and provide a cytoprotective activity in experimental models of oxidative stress [126]. A derivative of TEMPOL coupled to gramicidin $\mathrm{S}$ for mitochondrial targeting was protective in a rat model of lethal hemorrhagic shock, blocking activation of the pro-apoptotic caspases -3 and -7 [127]; extension of these studies to sepsis models would appear to hold merit.

\section{Conclusions}

Sepsis is an exaggerated and detrimental inflammatory response reflecting the host's desperate attempt to control an overwhelming infection. Within septic patients, specific cell populations are dying, and indeed so are the patients themselves. However, with the advent of antibiotic therapy and modern intensive care procedures for life support, physicians are in a position to rescue more sepsis patients through improved understanding of the fundamental pathophysiology, including the prominent role of cell death. While apoptosis has been the major focus of investigative attention, necrosis, pyroptosis and extracellular trap-associated cell death certainly also play important role in this disease. Indeed, a variety of modalities of cell death co-exist in septic patients and the ultimate clinical phenotype is the result not only of the cell populations lost, but also of the proinflammatory and antiinflammatory effects of necrotic and apoptotic cells (respectively) on macrophage and dendritic cell function (Fig. 3). Moreover, specific virulence factors expressed by individual inciting bacterial pathogen(s) may skew the frequency and distribution of cell death phenotypes and thus the tempo and severity of illness.

It is apparent that cell disintegration, and the molecules thereby released, plays a governing roles in the inflammatory response and host immune competence during sepsis.
Comprehension of the molecular mechanisms implicated in this phenomenon might lead to the development of therapeutic strategies targeted against dying cells and the signals they transmit, thereby mitigating their negative effects.

Acknowledgments Cited work of the VN laboratory in this area was supported by NIH grant AI077780. FPS is supported by CAPES (Ministry of Sciences, Brazil).

Open Access This article is distributed under the terms of the Creative Commons Attribution Noncommercial License which permits any noncommercial use, distribution, and reproduction in any medium, provided the original author(s) and source are credited.

\section{References}

1. Martin GS, Mannino DM, Eaton S, Moss M (2003) The epidemiology of sepsis in the United States from 1979 through 2000. N Engl J Med 348:1546-1554. doi:10.1056/NEJMoa0 22139

2. Bone RC, Balk RA, Cerra FB et al (1992) Definitions for sepsis and organ failure and guidelines for the use of innovative therapies in sepsis. The ACCP/SCCM Consensus Conference Committee. American College of Chest Physicians/Society of Critical Care Medicine. Chest 101:1644-1655. doi:10.1378/ chest.101.6.1644

3. Hotchkiss RS, Karl IE (2003) The pathophysiology and treatment of sepsis. N Engl J Med 348:138-150. doi:10.1056/ NEJMra021333

4. Bone RC, Grodzin CJ, Balk RA (1997) Sepsis: a new hypothesis for pathogenesis of the disease process. Chest 112:235-243. doi: 10.1378/chest.112.1.235

5. Bone RC (1996) Sir Isaac Newton, sepsis, SIRS, and CARS. Crit Care Med 24:1125-1128. doi:10.1097/00003246-1996070 00-00010

6. Yasuhara S, Asai A, Sahani ND, Martyn JA (2007) Mitochondria, endoplasmic reticulum, and alternative pathways of cell death in critical illness. Crit Care Med 35:S488-S495. doi: 10.1097/01.CCM.0000278045.91575.30

7. Klionsky DJ (2004) Cell biology: regulated self-cannibalism. Nature 431:31-32. doi:10.1038/431031a

8. Rodriguez-Enriquez S, He L, Lemasters JJ (2004) Role of mitochondrial permeability transition pores in mitochondrial autophagy. Int J Biochem Cell Biol 36:2463-2472. doi:10.1016/ j.biocel.2004.04.009

9. Rock KL, Kono H (2008) The inflammatory response to cell death. Annu Rev Pathol 3:99-126. doi:10.1146/annurev.path mechdis.3.121806.151456

10. Scaffidi P, Misteli T, Bianchi ME (2002) Release of chromatin protein HMGB1 by necrotic cells triggers inflammation. Nature 418:191-195. doi:10.1038/nature00858

11. Chen CJ, Kono H, Golenbock D, Reed G, Akira S, Rock KL (2007) Identification of a key pathway required for the sterile inflammatory response triggered by dying cells. Nat Med 13:851-856. doi:10.1038/nm1603

12. Martinon F, Petrilli V, Mayor A, Tardivel A, Tschopp J (2006) Gout-associated uric acid crystals activate the NALP3 inflammasome. Nature 440:237-241. doi:10.1038/nature04516

13. Hefeneider SH, Cornell KA, Brown LE, Bakke AC, McCoy SL, Bennett RM (1992) Nucleosomes and DNA bind to specific cellsurface molecules on murine cells and induce cytokine production. Clin Immunol Immunopathol 63:245-251. doi:10.1016/ 0090-1229(92)90229-H 
14. Tsan MF, Gao B (2004) Cytokine function of heat shock proteins. Am J Physiol Cell Physiol 286:C739-C744. doi:10.1152/ ajpcell.00364.2003

15. Wallin RP, Lundqvist A, More SH, von Bonin A, Kiessling R, Ljunggren HG (2002) Heat-shock proteins as activators of the innate immune system. Trends Immunol 23:130-135. doi: 10.1016/S1471-4906(01)02168-8

16. Zanetti M (2004) Cathelicidins, multifunctional peptides of the innate immunity. J Leukoc Biol 75:39-48. doi:10.1189/jlb. 0403147

17. Mariathasan S, Monack DM (2007) Inflammasome adaptors and sensors: intracellular regulators of infection and inflammation. Nat Rev Immunol 7:31-40. doi:10.1038/nri1997

18. Cavassani KA, Ishii M, Wen $H$ et al (2008) TLR3 is an endogenous sensor of tissue necrosis during acute inflammatory events. J Exp Med 205:2609-2621. doi:10.1084/jem.20081370

19. Yamasaki S, Ishikawa E, Sakuma M, Hara H, Ogata K, Saito T (2008) Mincle is an ITAM-coupled activating receptor that senses damaged cells. Nat Immunol 9:1179-1188. doi:10.1038/ ni. 1651

20. Thornberry NA, Lazebnik Y (1998) Caspases: enemies within. Science 281:1312-1316. doi:10.1126/science.281.5381.1312

21. Hail N Jr, Carter BZ, Konopleva M, Andreeff M (2006) Apoptosis effector mechanisms: a requiem performed in different keys. Apoptosis 11:889-904. doi:10.1007/s10495-006$6712-8$

22. Hengartner MO (2000) The biochemistry of apoptosis. Nature 407:770-776. doi:10.1038/35037710

23. Strasser A, O'Connor L, Dixit VM (2000) Apoptosis signaling. Annu Rev Biochem 69:217-245. doi:10.1146/annurev.biochem. 69.1.217

24. Turk B, Stoka V (2007) Protease signalling in cell death: caspases versus cysteine cathepsins. FEBS Lett 581:2761-2767. doi:10.1016/j.febslet.2007.05.038

25. Ashkenazi A, Dixit VM (1998) Death receptors: signaling and modulation. Science 281:1305-1308. doi:10.1126/science.281. 5381.1305

26. Muppidi JR, Tschopp J, Siegel RM (2004) Life and death decisions: secondary complexes and lipid rafts in TNF receptor family signal transduction. Immunity 21:461-465. doi:10.1016/ j.immuni.2004.10.001

27. Muchmore SW, Sattler M, Liang H et al (1996) X-ray and NMR structure of human Bcl-xL, an inhibitor of programmed cell death. Nature 381:335-341. doi:10.1038/381335a0

28. Minn AJ, Velez P, Schendel SL et al (1997) Bcl-x(L) forms an ion channel in synthetic lipid membranes. Nature 385:353-357. doi: $10.1038 / 385353 \mathrm{a} 0$

29. Antonsson B, Conti F, Ciavatta A et al (1997) Inhibition of Bax channel-forming activity by Bcl-2. Science 277:370-372. doi: 10.1126/science.277.5324.370

30. Bayir H, Kagan VE (2008) Bench-to-bedside review: Mitochondrial injury, oxidative stress and apoptosis-there is nothing more practical than a good theory. Crit Care 12:206. doi: $10.1186 /$ cc6779

31. Nakagawa T, Zhu H, Morishima N et al (2000) Caspase-12 mediates endoplasmic-reticulum-specific apoptosis and cytotoxicity by amyloid-beta. Nature 403:98-103. doi:10.1038/47513

32. Di Sano F, Ferraro E, Tufi R, Achsel T, Piacentini M, Cecconi F (2006) Endoplasmic reticulum stress induces apoptosis by an apoptosome-dependent but caspase 12-independent mechanism. J Biol Chem 281:2693-2700. doi:10.1074/jbc.M509110200

33. Oyadomari S, Mori M (2004) Roles of CHOP/GADD153 in endoplasmic reticulum stress. Cell Death Differ 11:381-389. doi:10.1038/sj.cdd.4401373
34. Saleh M, Mathison JC, Wolinski MK et al (2006) Enhanced bacterial clearance and sepsis resistance in caspase-12-deficient mice. Nature 440:1064-1068. doi:10.1038/nature04656

35. Leist M, Jaattela M (2001) Triggering of apoptosis by cathepsins. Cell Death Differ 8:324-326. doi:10.1038/sj.cdd.4400859

36. Johnson DE (2000) Noncaspase proteases in apoptosis. Leukemia 14:1695-1703. doi:10.1038/sj.leu.2401879

37. Zavasnik-Bergant T, Turk B (2006) Cysteine cathepsins in the immune response. Tissue Antigens 67:349-355. doi:10.1111/ j.1399-0039.2006.00585.x

38. Zavasnik-Bergant T, Turk B (2007) Cysteine proteases: destruction ability versus immunomodulation capacity in immune cells. Biol Chem 388:1141-1149. doi:10.1515/BC. 2007.144

39. Chwieralski CE, Welte T, Buhling F (2006) Cathepsin-regulated apoptosis. Apoptosis 11:143-149. doi:10.1007/s10495-0063486-y

40. Kagedal K, Zhao M, Svensson I, Brunk UT (2001) Sphingosineinduced apoptosis is dependent on lysosomal proteases. Biochem J 359:335-343. doi:10.1042/0264-6021:3590335

41. Zdolsek J, Zhang H, Roberg K, Brunk U (1993) $\mathrm{H}_{2} \mathrm{O}_{2}$-mediated damage to lysosomal membranes of J-774 cells. Free Radic Res Commun 18:71-85. doi:10.3109/10715769309147344

42. Bursch W (2001) The autophagosomal-lysosomal compartment in programmed cell death. Cell Death Differ 8:569-581. doi: 10.1038/sj.cdd. 4400852

43. Kobayashi SD, Braughton KR, Whitney AR et al (2003) Bacterial pathogens modulate an apoptosis differentiation program in human neutrophils. Proc Natl Acad Sci USA 100:1094810953. doi:10.1073/pnas. 1833375100

44. Timmer AM, Timmer JC, Pence MA et al (2009) Streptolysin O promotes group a streptococcus immune evasion by accelerated macrophage apoptosis. J Biol Chem 284:862-871. doi: 10.1074/jbc.M804632200

45. Lee SW, Mitchell DA, Markley AL et al (2008) Discovery of a widely distributed toxin biosynthetic gene cluster. Proc Natl Acad Sci USA 105:5879-5884. doi:10.1073/pnas.0801338105

46. Datta V, Myskowski SM, Kwinn LA et al (2005) Mutational analysis of the group A streptococcal operon encoding streptolysin $\mathrm{S}$ and its virulence role in invasive infection. Mol Microbiol 56:681-695. doi:10.1111/j.1365-2958.2005.04583.x

47. Goldmann O, Sastalla I, Wos-Oxley M, Rohde M, Medina E (2009) Streptococcus pyogenes induces oncosis in macrophages through the activation of an inflammatory programmed cell death pathway. Cell Microbiol 11:138-155

48. Rogers HW, Callery MP, Deck B, Unanue ER (1996) Listeria monocytogenes induces apoptosis of infected hepatocytes. J Immunol 156:679-684

49. Merrick JC, Edelson BT, Bhardwaj V, Swanson PE, Unanue ER (1997) Lymphocyte apoptosis during early phase of Listeria infection in mice. Am J Pathol 151:785-792

50. Guzman CA, Domann E, Rohde M et al (1996) Apoptosis of mouse dendritic cells is triggered by listeriolysin, the major virulence determinant of Listeria monocytogenes. Mol Microbiol 20:119-126. doi:10.1111/j.1365-2958.1996.tb02494.x

51. Bayles KW, Wesson CA, Liou LE, Fox LK, Bohach GA, Trumble WR (1998) Intracellular Staphylococcus aureus escapes the endosome and induces apoptosis in epithelial cells. Infect Immun 66:336-342

52. Wesson CA, Deringer J, Liou LE, Bayles KW, Bohach GA, Trumble WR (2000) Apoptosis induced by Staphylococcus aureus in epithelial cells utilizes a mechanism involving caspases 8 and 3. Infect Immun 68:2998-3001. doi:10.1128/IAI.68. 5.2998-3001.2000 
53. Gao LY, Kwaik YA (2000) The modulation of host cell apoptosis by intracellular bacterial pathogens. Trends Microbiol 8:306-313. doi:10.1016/S0966-842X(00)01784-4

54. Prince LR, Bianchi SM, Vaughan KM et al (2008) Subversion of a lysosomal pathway regulating neutrophil apoptosis by a major bacterial toxin, pyocyanin. J Immunol 180:3502-3511

55. Smith JL, Bayles DO (2006) The contribution of cytolethal distending toxin to bacterial pathogenesis. Crit Rev Microbiol 32:227-248. doi:10.1080/10408410601023557

56. Damle NK, Leytze G, Klussman K, Ledbetter JA (1993) Activation with superantigens induces programmed death in antigen-primed CD4 + class II + major histocompatibility complex T lymphocytes via a CD11a/CD18-dependent mechanism. Eur J Immunol 23:1513-1522. doi:10.1002/eji.1830230 718

57. Hofer MF, Newell K, Duke RC, Schlievert PM, Freed JH, Leung DY (1996) Differential effects of staphylococcal toxic shock syndrome toxin-1 on B cell apoptosis. Proc Natl Acad Sci USA 93:5425-5430. doi:10.1073/pnas.93.11.5425

58. Watanabe-Ohnishi R, Low DE, McGeer A et al (1995) Selective depletion of $\mathrm{V}$ beta-bearing $\mathrm{T}$ cells in patients with severe invasive group A streptococcal infections and streptococcal toxic shock syndrome Ontario Streptococcal study project. J Infect Dis 171:74-84

59. Grassme H, Kirschnek S, Riethmueller J et al (2000) CD95/ CD95 ligand interactions on epithelial cells in host defense to Pseudomonas aeruginosa. Science 290:527-530. doi:10.1126/ science.290.5491.527

60. Lara-Tejero M, Sutterwala FS, Ogura Y et al (2006) Role of the caspase-1 inflammasome in Salmonella typhimurium pathogenesis. J Exp Med 203:1407-1412. doi:10.1084/jem.20060 206

61. Fink SL, Cookson BT (2007) Pyroptosis and host cell death responses during Salmonella infection. Cell Microbiol 9:25622570. doi:10.1111/j.1462-5822.2007.01036.x

62. Cookson BT, Brennan MA (2001) Pro-inflammatory programmed cell death. Trends Microbiol 9:113-114. doi:10.1016/ S0966-842X(00)01936-3

63. Scott AM, Saleh M (2007) The inflammatory caspases: guardians against infections and sepsis. Cell Death Differ 14:23-31. doi:10.1038/sj.cdd.4402026

64. Wang S, Miura M, Jung YK, Zhu H, Li E, Yuan J (1998) Murine caspase-11, an ICE-interacting protease, is essential for the activation of ICE. Cell 92:501-509. doi:10.1016/S0092-8674 (00)80943-5

65. Mueller NJ, Wilkinson RA, Fishman JA (2002) Listeria monocytogenes infection in caspase-11-deficient mice. Infect Immun 70:2657-2664. doi:10.1128/IAI.70.5.2657-2664.2002

66. Martinon F, Tschopp J (2007) Inflammatory caspases and inflammasomes: master switches of inflammation. Cell Death Differ 14:10-22. doi:10.1038/sj.cdd.4402038

67. Meylan E, Tschopp J, Karin M (2006) Intracellular pattern recognition receptors in the host response. Nature 442:39-44. doi:10.1038/nature04946

68. Petrilli V, Dostert C, Muruve DA, Tschopp J (2007) The inflammasome: a danger sensing complex triggering innate immunity. Curr Opin Immunol 19:615-622. doi:10.1016/j.coi. 2007.09.002

69. Perregaux D, Gabel CA (1994) Interleukin-1 beta maturation and release in response to ATP and nigericin. Evidence that potassium depletion mediated by these agents is a necessary and common feature of their activity. J Biol Chem 269:15195-15203

70. Becker CE, O'Neill LA (2007) Inflammasomes in inflammatory disorders: the role of TLRs and their interactions with NLRs. Semin Immunopathol 29:239-248. doi:10.1007/s00281-0070081-4
71. Church LD, Cook GP, McDermott MF (2008) Primer: inflammasomes and interleukin 1beta in inflammatory disorders. Nat Clin Pract Rheumatol 4:34-42. doi:10.1038/ncprheum0681

72. Franchi L, Amer A, Body-Malapel M et al (2006) Cytosolic flagellin requires IPAF for activation of caspase-1 and interleukin $1 \beta$ in Salmonella-infected macrophages. Nat Immunol 7:576-582. doi:10.1038/ni1346

73. Coers J, Vance RE, Fontana MF, Dietrich WF (2007) Restriction of Legionella pneumophila growth in macrophages requires the concerted action of cytokine and Naip5/IPAF signalling pathways. Cell Microbiol 9:2344-2357. doi:10.1111/j.14625822.2007.00963.x

74. Lamkanfi M, Kanneganti TD, Franchi L, Nunez G (2007) Caspase-1 inflammasomes in infection and inflammation. $\mathrm{J}$ Leukoc Biol 82:220-225. doi:10.1189/jlb.1206756

75. Ogura Y, Sutterwala FS, Flavell RA (2006) The inflammasome: first line of the immune response to cell stress. Cell 126:659662. doi:10.1016/j.cell.2006.08.002

76. Li P, Allen H, Banerjee S et al (1995) Mice deficient in IL-1 $\beta$ converting enzyme are defective in production of mature IL- $1 \beta$ and resistant to endotoxic shock. Cell 80:401-411. doi: 10.1016/0092-8674(95)90490-5

77. Brinkmann V, Reichard U, Goosmann C et al (2004) Neutrophil extracellular traps kill bacteria. Science 303:1532-1535. doi: 10.1126/science. 1092385

78. Fuchs TA, Abed U, Goosmann C et al (2007) Novel cell death program leads to neutrophil extracellular traps. J Cell Biol 176:231-241. doi:10.1083/jcb.200606027

79. Wartha F, Henriques-Normark B (2008) ETosis: a novel cell death pathway. Sci Signal 1:pe25. doi:10.1126/stke.121pe25

80. Clark SR, Ma AC, Tavener SA et al (2007) Platelet TLR4 activates neutrophil extracellular traps to ensnare bacteria in septic blood. Nat Med 13:463-469. doi:10.1038/nm1565

81. Ma AC, Kubes P (2008) Platelets, neutrophils, and neutrophil extracellular traps (NETs) in sepsis. J Thromb Haemost 6:415420. doi:10.1111/j.1538-7836.2007.02865.x

82. Urban CF, Reichard U, Brinkmann V, Zychlinsky A (2006) Neutrophil extracellular traps capture and kill Candida albicans yeast and hyphal forms. Cell Microbiol 8:668-676. doi: 10.1111/j.1462-5822.2005.00659.x

83. Brinkmann V, Zychlinsky A (2007) Beneficial suicide: why neutrophils die to make NETs. Nat Rev Microbiol 5:577-582. doi: $10.1038 /$ nrmicro 1710

84. Margraf S, Logters T, Reipen J, Altrichter J, Scholz M, Windolf J (2008) Neutrophil-derived circulating free DNA (cf-DNA/ NETs): a potential prognostic marker for posttraumatic development of inflammatory second hit and sepsis. Shock 30:352358. doi:10.1097/SHK.0b013e31816a6bb1

85. Lauth $\mathrm{X}$, von Köckritz-Blickwede $\mathrm{M}$, McNamara $\mathrm{CW}$, et al. (2009) M1 protein allows group A streptococcal survival in phagocyte extracellular traps through cathelicidin inhibition. J Innate Immun (in press)

86. Zinkernagel AS, Timmer AM, Pence MA et al (2008) The IL-8 protease SpyCEP/ScpC of group A Streptococcus promotes resistance to neutrophil killing. Cell Host Microbe 4:170-178. doi:10.1016/j.chom.2008.07.002

87. Beiter K, Wartha F, Albiger B, Normark S, Zychlinsky A, Henriques-Normark B (2006) An endonuclease allows Streptococcus pneumoniae to escape from neutrophil extracellular traps. Curr Biol 16:401-407. doi:10.1016/j.cub.2006.01.056

88. Buchanan JT, Simpson AJ, Aziz RK et al (2006) DNase expression allows the pathogen group A Streptococcus to escape killing in neutrophil extracellular traps. Curr Biol 16:396-400. doi:10.1016/j.cub.2005.12.039

89. Walker MJ, Hollands A, Sanderson-Smith ML et al (2007) DNase Sda1 provides selection pressure for a switch to invasive 
group A streptococcal infection. Nat Med 13:981-985. doi: $10.1038 / \mathrm{nm} 1612$

90. Hotchkiss RS, Tinsley KW, Swanson PE et al (2001) Sepsisinduced apoptosis causes progressive profound depletion of $\mathrm{B}$ and CD4 + T lymphocytes in humans. J Immunol 166:69526963

91. Felmet KA, Hall MW, Clark RS, Jaffe R, Carcillo JA (2005) Prolonged lymphopenia, lymphoid depletion, and hypoprolactinemia in children with nosocomial sepsis and multiple organ failure. J Immunol 174:3765-3772

92. Toti P, De Felice C, Occhini R et al (2004) Spleen depletion in neonatal sepsis and chorioamnionitis. Am J Clin Pathol 122:765-771. doi:10.1309/RV6E9BMC9954A2WU

93. Le Tulzo Y, Pangault C, Gacouin A et al (2002) Early circulating lymphocyte apoptosis in human septic shock is associated with poor outcome. Shock 18:487-494. doi:10.1097/000243 82-200212000-00001

94. Hotchkiss RS, Tinsley KW, Swanson PE et al (2002) Depletion of dendritic cells, but not macrophages, in patients with sepsis. J Immunol 168:2493-2500

95. Hiramatsu M, Hotchkiss RS, Karl IE, Buchman TG (1997) Cecal ligation and puncture (CLP) induces apoptosis in thymus, spleen, lung, and gut by an endotoxin and TNF-independent pathway. Shock 7:247-253. doi:10.1097/00024382-19970400000002

96. Tinsley KW, Grayson MH, Swanson PE et al (2003) Sepsis induces apoptosis and profound depletion of splenic interdigitating and follicular dendritic cells. J Immunol 171:909-914

97. Coopersmith CM, Stromberg PE, Dunne WM et al (2002) Inhibition of intestinal epithelial apoptosis and survival in a murine model of pneumonia-induced sepsis. JAMA 287:17161721. doi:10.1001/jama.287.13.1716

98. Perl M, Chung CS, Lomas-Neira J et al (2005) Silencing of Fas, but not caspase-8, in lung epithelial cells ameliorates pulmonary apoptosis, inflammation, and neutrophil influx after hemorrhagic shock and sepsis. Am J Pathol 167:1545-1559

99. Wesche-Soldato DE, Chung CS, Gregory SH, Salazar-Mather TP, Ayala CA, Ayala A (2007) CD8 + T cells promote inflammation and apoptosis in the liver after sepsis: role of FasFasL. Am J Pathol 171:87-96. doi:10.2353/ajpath.2007.061099

100. Mutunga M, Fulton B, Bullock R et al (2001) Circulating endothelial cells in patients with septic shock. Am J Respir Crit Care Med 163:195-200

101. Hotchkiss RS, Nicholson DW (2006) Apoptosis and caspases regulate death and inflammation in sepsis. Nat Rev Immunol 6:813-822. doi:10.1038/nri1943

102. Green DR, Beere HM (2000) Apoptosis gone but not forgotten. Nature 405:28-29. doi:10.1038/35011175

103. Albert ML (2004) Death-defying immunity: do apoptotic cells influence antigen processing and presentation? Nat Rev Immunol 4:223-231. doi:10.1038/nri11308

104. van Dissel JT, van Langevelde P, Westendorp RG, Kwappenberg K, Frolich M (1998) Anti-inflammatory cytokine profile and mortality in febrile patients. Lancet 351:950-953

105. Rothlin CV, Ghosh S, Zuniga EI, Oldstone MB, Lemke G (2007) TAM receptors are pleiotropic inhibitors of the innate immune response. Cell 131:1124-1136. doi:10.1016/j.cell.2007. 10.034

106. Karin M, Lawrence T, Nizet V (2006) Innate immunity gone awry: linking microbial infections to chronic inflammation and cancer. Cell 124:823-835. doi:10.1016/j.cell.2006.02.016

107. Hotchkiss RS, Chang KC, Grayson MH et al (2003) Adoptive transfer of apoptotic splenocytes worsens survival, whereas adoptive transfer of necrotic splenocytes improves survival in sepsis. Proc Natl Acad Sci USA 100:6724-6729. doi:10.1073/ pnas. 1031788100
108. Brealey D, Brand M, Hargreaves I et al (2002) Association between mitochondrial dysfunction and severity and outcome of septic shock. Lancet 360:219-223. doi:10.1016/S0140-6736(02) 09459-X

109. Llesuy S, Evelson P, Gonzalez-Flecha B et al (1994) Oxidative stress in muscle and liver of rats with septic syndrome. Free Radic Biol Med 16:445-451. doi:10.1016/0891-5849(94)90 $121-\mathrm{X}$

110. Hotchkiss RS, Swanson PE, Knudson CM et al (1999) Overexpression of Bcl-2 in transgenic mice decreases apoptosis and improves survival in sepsis. J Immunol 162:4148-4156

111. Wesche-Soldato DE, Chung CS, Lomas-Neira J, Doughty LA, Gregory SH, Ayala A (2005) In vivo delivery of caspase- 8 or Fas siRNA improves the survival of septic mice. Blood 106:2295-2301. doi:10.1182/blood-2004-10-4086

112. Chang KC, Unsinger J, Davis CG et al (2007) Multiple triggers of cell death in sepsis: death receptor and mitochondrial-mediated apoptosis. FASEB J 21:708-719. doi:10.1096/fj.06$6805 \mathrm{com}$

113. Chung CS, Song GY, Lomas J, Simms HH, Chaudry IH, Ayala A (2003) Inhibition of Fas/Fas ligand signaling improves septic survival: differential effects on macrophage apoptotic and functional capacity. J Leukoc Biol 74:344-351. doi:10.1189/jlb. 0102006

114. Efron PA, Tinsley K, Minnich DJ et al (2004) Increased lymphoid tissue apoptosis in baboons with bacteremic shock. Shock 21:566-571. doi:10.1097/01.shk.0000126648.58732.8c

115. Hotchkiss RS, Osmon SB, Chang KC, Wagner TH, Coopersmith CM, Karl IE (2005) Accelerated lymphocyte death in sepsis occurs by both the death receptor and mitochondrial pathways. J Immunol 174:5110-5118

116. Pinheiro-da-Silva F, Chiamolera M, Charles N et al (2006) B lymphocytes undergo apoptosis because of Fc $\gamma \mathrm{RIIb}$ stress response to infection: a novel mechanism of cell death in sepsis. Shock 25:61-65. doi:10.1097/01.shk.0000196496.72553.78

117. van den Berghe G, Wouters P, Weekers F et al (2001) Intensive insulin therapy in the critically ill patients. $\mathrm{N}$ Engl $\mathrm{J}$ Med 345:1359-1367. doi:10.1056/NEJMoa011300

118. Bernard GR, Vincent JL, Laterre PF et al (2001) Efficacy and safety of recombinant human activated protein $\mathrm{C}$ for severe sepsis. N Engl J Med 344:699-709. doi:10.1056/NEJM200 103083441001

119. Wesche-Soldato DE, Swan RZ, Chung CS, Ayala A (2007) The apoptotic pathway as a therapeutic target in sepsis. Curr Drug Targets 8:493-500. doi:10.2174/138945007780362764

120. Zdychova J, Komers R (2005) Emerging role of Akt kinase/ protein kinase B signaling in pathophysiology of diabetes and its complications. Physiol Res 54:1-16

121. Joyce DE, Nelson DR, Grinnell BW (2004) Leukocyte and endothelial cell interactions in sepsis: relevance of the protein $\mathrm{C}$ pathway. Crit Care Med 32:S280-S286. doi:10.1097/01.CCM. 0000128037.72072 .22

122. Joyce DE, Gelbert L, Ciaccia A, DeHoff B, Grinnell BW (2001) Gene expression profile of antithrombotic protein $\mathrm{C}$ defines new mechanisms modulating inflammation and apoptosis. J Biol Chem 276:11199-11203. doi:10.1074/jbc.C100017200

123. Hotchkiss RS, Tinsley KW, Swanson PE et al (1999) Prevention of lymphocyte cell death in sepsis improves survival in mice. Proc Natl Acad Sci USA 96:14541-14546. doi:10.1073/pnas. 96.25.14541

124. Weaver JG, Rouse MS, Steckelberg JM, Badley AD (2004) Improved survival in experimental sepsis with an orally administered inhibitor of apoptosis. FASEB J 18:1185-1191. doi:10.1096/fj.03-1230com

125. Chung CS, Yang S, Song GY et al (2001) Inhibition of Fas signaling prevents hepatic injury and improves organ blood flow 
during sepsis. Surgery 130:339-345. doi:10.1067/msy.2001. 116540

126. Karmeli F, Eliakim R, Okon E, Samuni A, Rachmilewitz D (1995) A stable nitroxide radical effectively decreases mucosal damage in experimental colitis. Gut 37:386-393. doi: $10.1136 /$ gut.37.3.386
127. Macias CA, Chiao JW, Xiao J et al (2007) Treatment with a novel hemigramicidin-TEMPO conjugate prolongs survival in a rat model of lethal hemorrhagic shock. Ann Surg 245:305-314. doi:10.1097/01.sla.0000236626.57752.8e 